\title{
Uma proposta de pesquisa com o uso dos mapas sobre as vivências na educação infantil
}

\section{A research proposal using maps on experiences in Early Childhood Education}

Daniel Poio Roberti é Graduado em Geografia pela Universidade Federal Fluminense (2007) e doutor em Educação pela UFF (2015). Atualmente, é professor adjunto da área de Fundamentos da Educação e Geografia do curso de Geografia da Universidade Federal Fluminense (IEAR) e integrante do Grupo de Pesquisa e Estudos em Geografia da Infância (GRUPEGI/Cnpq-UFF).

Contato: daroberti@yahoo.com.br

\section{Resumo}

0 projeto pesquisou propostas metodológicas que discutissem formas de as crianças representarem um espaço; no caso a creche em que elas convivem. A pesquisa se propôs a abrir "frentes de diálogos" com as áreas temáticas da Sociologia da Infância, Psicologia do Desenvolvimento e Geografia da Infância. Os estudos da Sociologia da Infância e o Construtivismo pedagógico reconhecem, entre outras coisas, o protagonismo do sujeito na formação da trajetória pelo conhecimento. Os sujeitos desta pesquisa são crianças com idade entre 5 e 6 anos que pensam, vivem e sentem o espaço. 0 movimento da Geografia da Infância reconhece o mapa (forma de representação) como instrumento básico que pode mediar a relação do sujeito com o espaço; compreendendo assim que esta unidade (sujeito e espaço) é carregada de cultura e historicidade num cenário de permanente criação do sujeito.

Palavras-chave: Geografia da Infância. Sociologia da Infância. Teoria Histórico-Cultural. 


\begin{abstract}
The project researched methodological proposals that discussed children's ways of representing space; in this case, the nursery in which they stay. The research suggested to open "dialogue fronts" with the thematic areas of sociology of childhood, Developmental Psychology and Geography of Childhood. Sociology of childhood and pedagogical constructivism recognize, among other things, the protagonism of the subject in shaping the trajectory for knowledge. The subjects of this research are children aged between 5 and 6 years old who think, live and feel the space. Geography of Childhood recognize the map (form of representation) as a basic instrument that can mediate the relationship of the subject with space; thus understanding that this unit (subject and space) is loaded with culture and historicity in a scenario of permanent creation of the subject. Keywords: Geography of Childhood. Sociology of childhood. Historical-Cultural Theory.
\end{abstract}

\title{
Introdução
}

A Educação Infantil no Brasil foi subvalorizada pelas pesquisas acadêmicas até meados do século XXI. Um dos motivos para este fato pode ser explicado pelo tipo de público, originário das classes populares, que é preferencialmente atendido pelas creches e jardins de infância brasileiros (NUNES, 2013). A concepção que mais norteava as políticas governamentais para a creche no Brasil era a de caráter assistencialista, cujo princípio é o de "suprir as necessidades básicas (alimentação, saneamento e medicalização) das classes operárias e das famílias desvalidas" (REIS, 2013, p. 85).

Essa concepção assistencialista de Educação Infantil no Brasil acabou marginalizando os atores sociais que participaram mais desses espaços. As crianças se tornaram reféns das políticas normativas do Estado. A nossa pesquisa segue outra direção. 0 referencial teórico-metodológico da pesquisa buscou valorizar a participação ativa das crianças atendidas pela unidade de Educação Infantil onde ela foi realizada ao longo das diversas fases do projeto. É uma mudança de paradigma que pode contribuir para a formação de uma infância cidadã, plenamente consciente dos seus direitos e deveres. 
A Geografia sempre esteve ausente dessa discussão. Conteúdos, práticas e metodologias dessa disciplina não aparecem no currículo da Educação Infantil. Por muito tempo, as discussões teóricas do campo da infância ficaram restritas ao processo de alfabetização e desenvolvimento da competência da língua escrita, muito em função dos alarmantes índices de reprovação nas séries iniciais (SOARES, 2000). A partir dos anos 2000, a Geografia da Infância se constituiu enquanto campo acadêmico, em meio aos debates da literatura científica do segmento e políticas curriculares oficiais da área. Portanto, há toda uma história curricular inexplorada, e relevante, para a formação crítica do pesquisador que se dedique a esse campo.

Os objetivos gerais desta pesquisa foram relacionar os referenciais teórico-metodológicos da teoria histórico-cultural, Sociologia da Infância e o construtivismo pedagógico para discutir estratégias de pesquisa na Educação Infantil. Os objetivos específicos foram desenvolver práticas cartográficas que discutissem a relação entre a criança e o meio em que ela vive, produzindo assim um mapa sobre as vivências que abordassem a história de vida das crianças no espaço da instituição de Educação Infantil.

\section{Fundamentação teórica}

0 projeto de pesquisa se enquadra teoricamente no campo dos estudos contemporâneos da infância. Durante todo o século $X X$, a literatura científica compreendia a criança "como uma categoria genérica, um modelo ideal discutido em termos do desenvolvimento biológico. A partir de perspectivas filosóficas, da psicologia do desenvolvimento e da psicanálise, a criança vinha sendo estudada fora de um contexto social e de uma estrutura social" (TIBET, 2013, p. 15).

Sociologia da Infância é um campo que surge dos questionamentos em relação a uma visão da criança apenas enquanto ser biológico e individual. A nova corrente passa a defender o agenciamento infantil em relação às diversas modalidades de constrangimentos e impedimentos sociais (PROUT, 2010). Entendemos agenciamento infantil como formas de oportunizar a participação das crianças em diferentes assuntos que lhes digam respeito ou que as envolvam de alguma maneira. Alguns estudiosos do campo (PROUT, 2010; SARMENTO e MARCHI, 2008) interpretam a infância, vista como categoria social, em 
meio às estruturas sociais de coação; sejam elas classes sociais (burguesia), instituições de socialização (igreja, escola etc) ou a família (adultos). Em relação a esse movimento, os adultos passam a apresentar dois papéis na formação da personalidade das crianças, que se tornam excludentes; ou seja, colaborar com a formação do sujeito infantil emancipado ou impedir a valorização e o entendimento pelas crianças das suas práticas sociais (CORSARO, 1997). O nosso projeto escolheu o primeiro caminho epistemológico.

0 projeto busca problematizar os papéis assumidos pelo adulto e pela criança na pesquisa a partir de um olhar menos autoritário do primeiro em relação ao segundo. Pretendemos nos apropriar das discussões advindas do campo da Psicologia da Educação sobre o construtivismo pedagógico para entendermos mais sobre esse tema. Estamos convencidos de que há uma relação entre a Sociologia da Infância e o campo do construtivismo pedagógico, quando este, rechaçando o modelo do ensino tradicional, defende que o aluno (criança) produza conhecimento sobre o mundo. A figura do professor (adulto) é imprescindível nesse debate, porque ele é o responsável por mobilizar uma série de estratégias metodológicas com vistas a facilitar a descoberta da realidade pelo aluno. Por isso, afirmamos que a relação entre professores e alunos se torna indissociável no processo de ensino-aprendizagem. Acreditamos que essa relação possa ser considerada um valioso dado de pesquisa.

Uma das formas de a humanidade relacionar-se com o mundo é por intermédio do espaço. Mas não é o tipo de espaço fragmentado, congelado e precisamente memorizado pelos alunos em algumas aulas tradicionais de Geografia. 0 geógrafo Milton Santos (2000) descreve o espaço apresentando rusgos, sem o devido alinhamento geométrico da sua representação no mapa. Os rusgos são os movimentos humanos de transformação do espaço que não foram (carto)grafados pelo mapa oficial. 0 mapa é umas das formas possíveis de representação e registro gráfico do espaço. 0 mapa oficial, produzido por um órgão institucional, generaliza um jeito de representar uma dada realidade espacial. 0 ensino do mapa oficial tem o profícuo objetivo de mostrar para os alunos um mundo pronto e estável. 
Figura 1: Mapa-múndi político-administratrativo. Retirado do site http://revistaescola.abril.com.br/geografia/pratica-pedagogica/ serie/biodiversidade-costeira-duna-costoes-rochosos-manguezal-restinga-607180.shtml, no dia 15/03/2014.

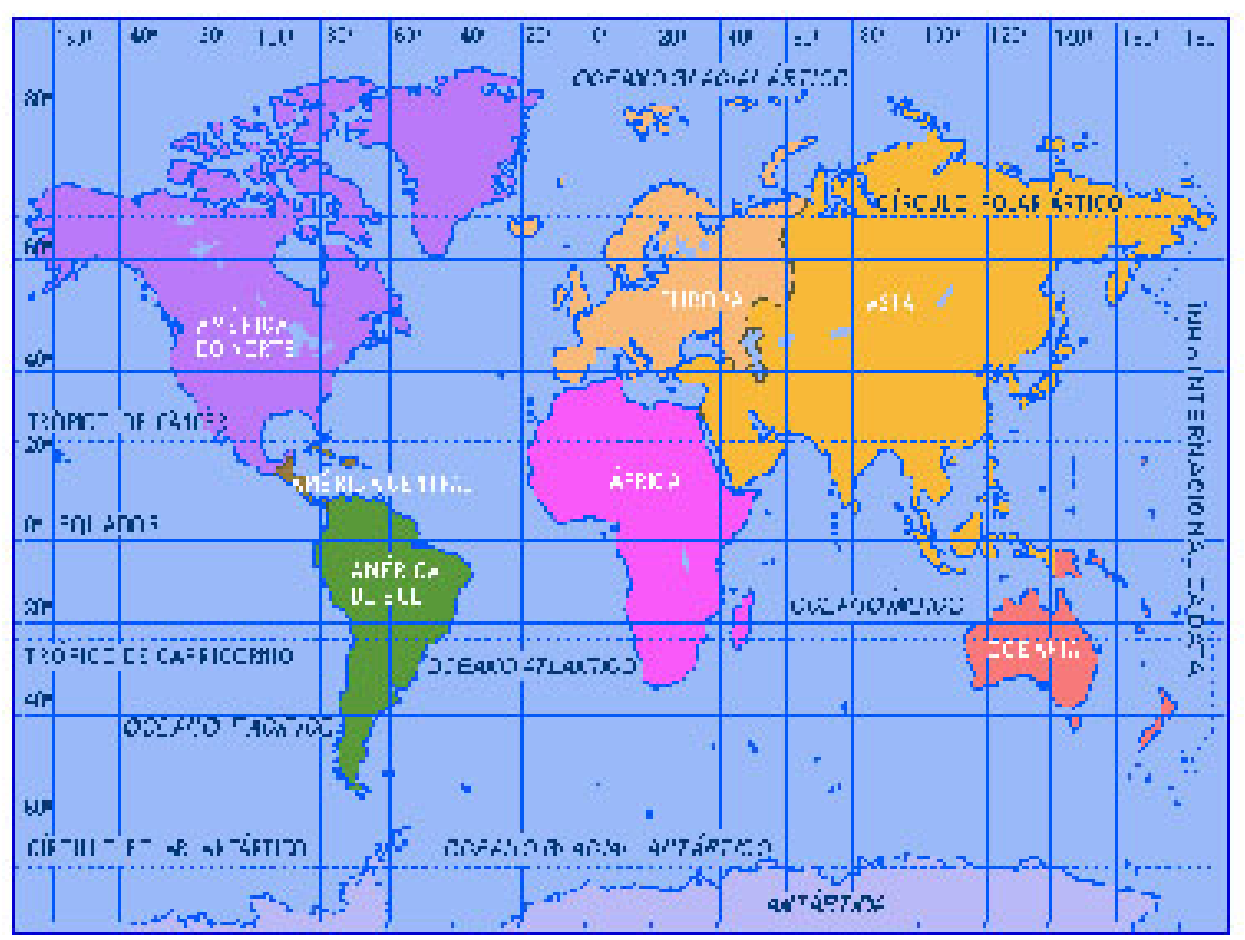

Talvez o maior símbolo do ensino do mapa oficial é o representado pela figura do mapa político-administrativo (OLIVEIRA JR, 2011). 0 autor deste projeto, em pesquisa de tese (2015), percebeu que as crianças, desde muito cedo, têm contato com algumas imagens-representações oficiais do mundo.

Figura 2: Desenho da Ana Júlia, aluna da creche, com 4 anos incompletos (28/09/2015).

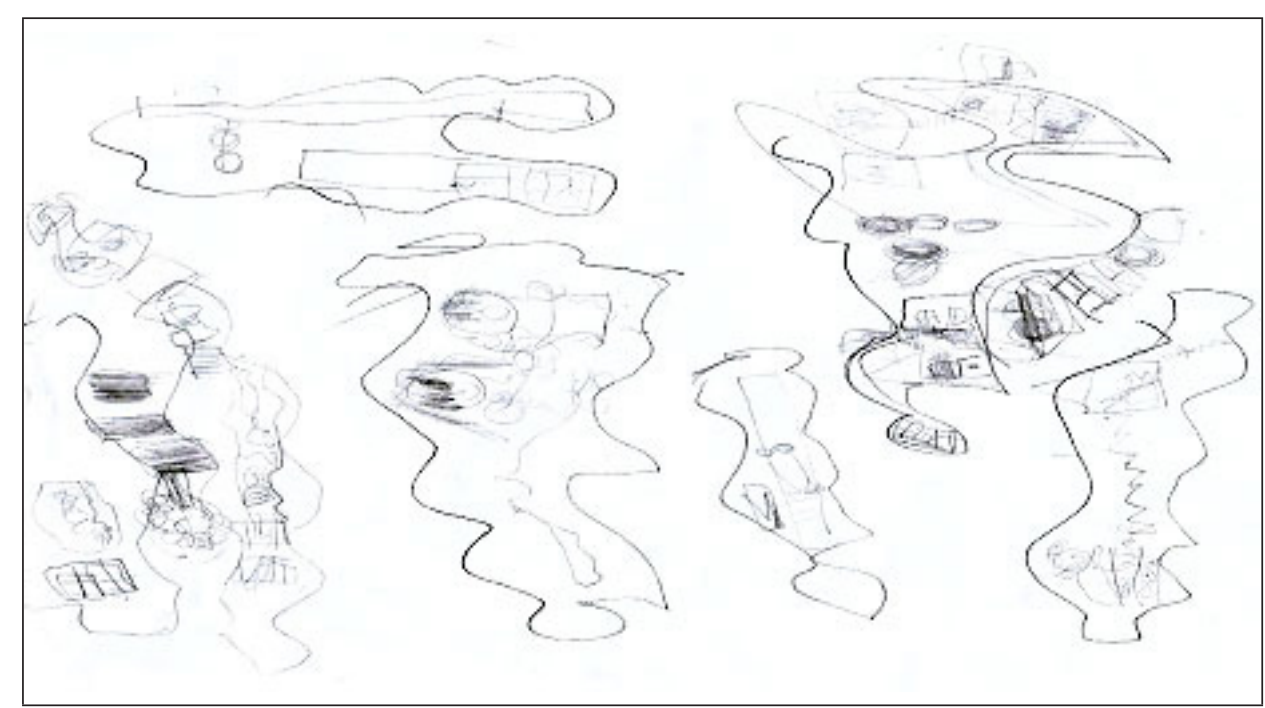

Discutindo a relação da imagem e a representação da criança, os pesquisadores (ROBERTI; LOPES, 2018) pediram para que 
as crianças desenhassem um mapa. Essas crianças nunca trabalharam com mapas, mas muitas delas, como a Ana Júlia, pelo que podemos inferir (re)conhecem as representações (carto) gráficas oficiais do mundo. Neste estudo, as crianças da creche também foram entrevistadas pelo pesquisador. 0 intuito das entrevistas era descobrir o que são aqueles desenhos e por que elas os fizeram. A partir dessas narrativas, os autores da pesquisa descobriram que o mapa da Ana Júlia à noite é iluminado por faróis, carros e barcos. Tem um mar entre a Índia e o Brasil; aliás, o nosso país é um caso à parte. Ele é "uma cidade" habitada por todo tipo de gente. É um mapa todo significado pela criança que vive o espaço.

Este estudo nos aponta que não podemos controlar o que, e de que forma, as crianças aprendem o mundo. As crianças, em atividades de cartografia não reproduzem fidedignamente o modelo de realidade espacial representado pelo mapa oficial; elas o reelaboram, deixando as suas marcas de infância. A cartografia escolar desenvolveu algumas metodologias para dar conta de entender o pensamento e a representação infantil.

0 campo da cartografia escolar, nos últimos 30 anos, desenvolveu uma série de metodologias para entender como o sujeito, particularmente as crianças, pensam e representam o mundo. A estratégia teórico-metodológica do mapa mental foi desenvolvida com o objetivo de cartografar o mundo humano, fugindo das relações racionalistas que marcavam os diversos campos do conhecimento no período entre o final do século XIX e início do século XX. Os seus principais conceitos são o de espaço vivido (LYNCH, 1997; FREMÓNT, 1976) e o de lugar (TUAN, 1980). Esses conceitos contribuíram para o entendimento do modo como os sujeitos interpretam e internalizam o mundo. Os mapas são analisados e categorizados, a partir do objetivo do investigador.

Outras possibilidades de entender como o sujeito pensa 0 mundo surgiram mais ou menos nesse mesmo contexto. Os mapas narrativos apresentam como conceito-chave o mundo vivido (BERGER e LUCKMANN, 1978; SCHUTZE, 2003). 0 principal movimento que influenciou essa metodologia foi a fenomenologia. Os mapas narrativos fazem parte de uma estratégia de pesquisa também conhecida como etnografia visual, em que o procedimento de coleta de dados prevê o uso das técnicas de desenho e narração, simultaneamente, pelo sujeito-alvo do estudo. A forma de tratamento dos resultados se assemelha à dos mapas mentais cujo pesquisador se torna o responsável pela 
interpretação e categorização das informações.

A metodologia de pesquisa dos mapas vivenciais se baseia na teoria histórico-cultural e nos conceitos de vivência e reelaboração criadora. Esses conceitos aparecem em obras diversas de Lev Vigotski (2006a, 2006b, 2009). A teoria histórico-cultural surgiu nos anos 30 do século passado, a partir de um grupo de pesquisadores soviéticos, do qual Vigotski fazia parte, que buscou "(...) reunir num mesmo modelo explicativo, tanto os mecanismos subjacentes ao funcionamento psicológico como a constituição de sujeito e da espécie humana ao longo de um processo históricocultural". (OLIVEIRA, 2005, p. 8)

Vigotski defendia que os movimentos epistemológicos de matrizes no racionalismo cartesiano, no interacionismo e na fenomenologia subjetiva não davam conta de discutir como o sujeito compreende o mundo, porque todos eles, de certa forma, separam a pessoa do próprio meio. Vigotski acredita que toda a produção humana advém da relação de unidade entre a pessoa e o mundo (vivência). Vigotski (1999, p. 686) definiu "vivência" como: uma unidade na qual, por um lado, de modo indivisível, o meio, aquilo que se vivencia está representado - a vivência sempre se liga àquilo que está localizado fora da pessoa - e, por outro lado, está representado como eu vivencio isso, ou seja, todas as particularidades da personalidade e todas as particularidades do meio são apresentadas na vivência, tanto aquilo que é retirado do meio, todos os elementos que possuem relação com dada personalidade, como aquilo que é retirado da personalidade, todos os traços de seu caráter, traços constitutivos que possuem relação com dado acontecimento. Dessa forma, na vivência, nós sempre lidamos com a união indivisível das particularidades da personalidade e das particularidades da situação representada na vivência.

Fato esse que pode ser complementado pelo conceito de reelaboração criadora cuja principal fonte de inspiração de Vigotski foi o pensamento de Marx: "Homens (sic) fazem a história, mas apenas sob as condições que lhes são dadas". A ideia do desenvolvimento da história pregressa do homem são as maiores contribuições do pensamento de Marx e de Vigostki para a nossa pesquisa. 0 sujeito, atravessado pela história, amplia as suas possibilidades de interpretar, combinar e criar algo novo no mundo.

A metodologia dos mapas vivenciais leva em conta a produção das pessoas em meio aos espaços já existentes na história 
humana. Essa metodologia se apropriou das discussões da Geografia sobre o conceito de espaço:

(...) devemos procurar entender o espaço como resultado de uma dinâmica e, então, dar condições ao aluno para que se situe neste processo. Deve-se reconhecer que é possível construir o espaço, e que a forma como ele se apresenta, no momento atual, é o resultado da história de quem vive nele e como vive nele. Vai daí que se torna necessário perceber que é possível construir o espaço em que se vive. Que ele é a aparência do resultado da luta dos homens pela sobrevivência num determinado lugar e num determinado tempo. (KAERCHER, 1999, p. 69)

0 modo de interpretar os dados dos mapas vivenciais busca uma "dialogia entre pesquisador e pesquisados sobre a produção final" (LOPES, 2012), não categorizando os achados de campo em unidades de pesquisa cujo controle se concentra na mão do investigador, mas na tentativa de encontrar a singularidade da relação entre sujeitos e espaço, como condição irrepetível do conhecimento humano (BAKHTIN, 1979).

Além disso, acreditamos que a metodologia dos mapas vivenciais é a que mais se adequou às nossas intenções de pesquisa, porque é a única que consegue mapear os "rusgos" infantis, ou seja, as vivências infantis. É um tipo de vivência bem particular que é amalgamado pela relação de tutela do adulto. "Assim toda criança é criança de um local; de forma correspondente, para cada criança do local existe também um lugar de criança, um lugar social designado pelo mundo adulto e que configura os limites da sua vivência." (LOPES, 2005, p.39). Portanto, a pesquisa buscou mapear o "lugar social da criança" com os também participantes dessa infância: os adultos. Antes de chegarmos na representação desenvolvida, vamos discutir uma interessante experiência que fez uso da metodologia de pesquisa dos mapas vivenciais.

0 professor Reinaldo Lima (2014) construiu um mapa vivencial do centro da cidade de Areal. Esse município, de pouco mais de 11 mil habitantes, pertence à região centro-sul fluminense. Lima (2014) escolheu um grupo de alunos do primeiro segmento de uma escola municipal e particular de Areal para discutir a construção do mapa do centro da cidade. (Fig. 3) 
Figura 3: Mapa vivencial do centro da cidade de Areal.

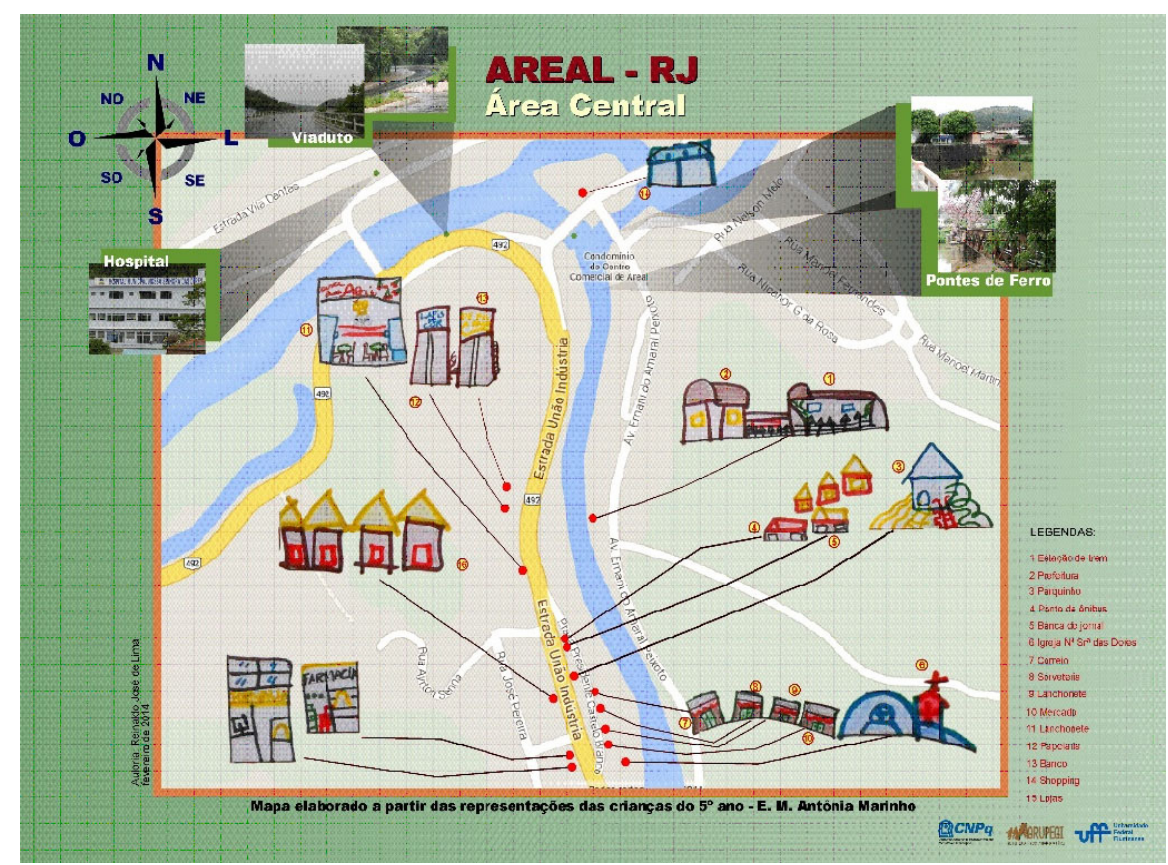

A base de dados cartográfica do mapa vivencial do centro de Areal veio do programa Google Maps. A cidade de Areal não aparece em nenhum mapa oficial. Esta metodologia corrobora com os pressupostos da teoria histórico-cultural de tentar mapear a autoria humana por dentro das entranhas do já existente, do que já está posto. Por isso, buscou-se alguma base de dados já catalogados, caso do Google Maps. 0 objetivo do uso dessa plataforma foi fugir da ideia dos mapas (mentais) imaginativos.

Os adultos, que moram no centro de Areal também fizeram parte da pesquisa. Essa consulta foi importante para compreender o "lugar social da criança" designado pelo adulto e para comprovar uma das hipóteses de investigação do autor: dependendo do grupo, classe ou estrutura etária, os sujeitos observam o mundo de maneiras distintas.

\section{Metodologia}

Entendendo que toda metodologia é formada por um conjunto de técnicas, estratégias e práticas que dão conta de realizar uma pesquisa, elaboramos determinados procedimentos com vistas ao desenvolvimento do estudo:

- Levantamento de artigos, teses e livros que discutam a cultura da infância por meio, principalmente das abordagens da Sociologia da Infância, Geografia da Infância e Psicologia da Educação; 
- Entrada no campo para o desenvolvimento da metodologia de pesquisa qualitativa com coleta e interpretação dos dados sobre os mapas das vivenciais da Educação Infantil.

As estratégias metodológicas nas quais mais nos baseamos para a construção deste projeto foram a análise documental e a pesquisa qualitativa com o uso de entrevistas. A pesquisa documental seguiu uma abordagem que se orientou para as fontes, na qual o material de consulta sobre as diferentes concepções de infância e da Geografia no currículo da Educação Infantil suscitaram questões que o próprio projeto buscou discutir (DUFFY, 2008).

A pesquisa qualitativa "privilegia a compreensão dos comportamentos a partir da perspectiva dos sujeitos de investigação" (BIKLEN \& BOGDAN, 1994, p. 8). As estratégias de pesquisa qualitativa que utilizamos neste projeto foram a de observação-participante e as de entrevistas em profundidade. A prática da observação-participante pretende inserir o pesquisador no contexto do campo de investigação e as entrevistas de cunho semiestruturadas permitem que ele aprenda a lidar com os conflitos éticos de realizar uma pesquisa com professores (BIKLEN \& BOGDAN, 1994, p. 8) e com crianças pequenas (CORSARO, 1997).

A metodologia dos mapas sobre as vivências infantis foi dividida em quatro etapas. Primeiro, procuramos o mapa oficial da referida unidade de Educação Infantil em seu acervo cartográfico ou na Secretaria Municipal de Educação de Angra dos Reis. A ideia de representar a vivência dos sujeitos da Educação Infantil a partir dos mapas oficiais surge com a proposta de discutir a representação dos espaços instituídos, aqueles que foram planejados pelo adulto (arquiteto ou gestor da educação) para a realização de determinadas funções pelos seus usuários, principalmente as crianças nas instituições de ensino. Gostaríamos de ressaltar que esses usuários são protagonistas, e não coadjuvantes, no processo de apropriação do espaço da unidade de Educação Infantil. E que o nosso tipo de metodologia reconhece a condição cultural do sujeito, ou seja, independentemente da faixa etária, classe social e gênero todos os sujeitos são influenciados mutuamente nessa relação. 
Figura 4: Planta baixa da creche.

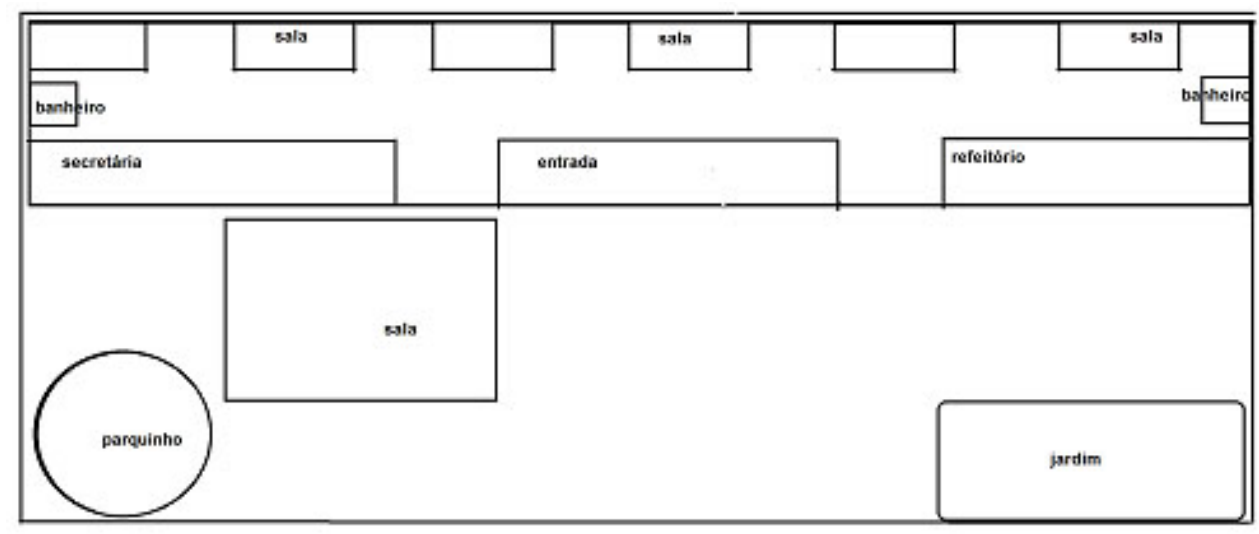

A segunda fase consistiu na realização de atividades com vistas ao desenvolvimento de habilidades e técnicas de percepção e representação do espaço, como o entendimento das relações topológicas (perto, longe, em cima e embaixo, direita, frente, esquerda e atrás), euclidianas (geométricas espaciais), visão vertical (de cima) e horizontal (de frente). Todas essas estratégias de intervenção foram avaliadas a partir da expressão oral e gráfica das crianças. Uma das atividades iniciou-se a partir de uma roda de conversa sobre a sala de aula e a história da unidade de Educação Infantil, com o objetivo de conhecer quais eram as impressões dos alunos sobre o espaço escolar. Depois, realizamos um passeio com as crianças para que elas (re)conhecessem os diferentes espaços da referida instituição. Por último, construímos uma maquete da mesma, com o uso de materiais reciclados

Realizamos também atividades que facilitassem o desenvolvimento espacial das crianças. Fizemos passeios na unidade de ensino e no bairro entorno, com o intuito de construirmos mapas topológicos e o reconhecimento dos tipos de perspectivas espaciais (LESSAN, 2011; PAGANELLI, 1982; SIMIELLI, 1996). Os alunos tiraram fotos dos espaços visitados e os representaram por meio de desenhos. Depois, apresentamos a imagem da instituição de ensino a partir do Google Maps. 0 objetivo dessas atividades foi discutir a mudança da perspectiva visual do espaço (visão horizontal/vertical da realidade). Essas atividades facilitaram o desenvolvimento da metodologia dos mapas sobre as vivências.

A segunda fase da pesquisa se preocupou com as formas de registrar os usos dos espaços da instituição de Educação Infantil, campo da pesquisa, pelas crianças. A prática dos mapas vivenciais trabalhou com a colocação de pranchas de papel vegetal sobre o mapa oficial do espaço a ser pesquisado, para que as crianças, 
funcionários e professores desenhassem suas vivências, criando mapas autorais.

A terceira fase foi marcada pela realização das entrevistas. Os entrevistados foram convidados a descrever os seus desenhos. 0 pesquisador interrogou alunos, funcionários e professores para tentar descobrir o porquê das escolhas de suas representações.

A quarta e última fase do projeto foi formada pela avaliação e pela discussão dos dados obtidos (desenhos e gravações) com os participantes da metodologia de pesquisa. 0 intuito dessa atividade foi selecionar falas e representações que depois fizeram parte do mapa sobre as vivências. A ideia é que todos os participantes da pesquisa (professores, funcionários e alunos das duas instituições) debatessem formas de representar o mapa da unidade de Educação Infantil.

\section{Considerações finais}

A pesquisa, desde o seu início, foi bem recebida pela equipe gestora, professores, funcionários e alunos da creche. Todos esses sujeitos, cada um a seu tempo, entenderam que o projeto apresentava uma metodologia diferenciada, que discutia 0 ensino de Geografia e cartografia na Educação Infantil. A despeito de alguns estudos da área (SIMIELLI, 1996) que apresentaram resultados satisfatórios no que diz respeito ao desenvolvimento espacial de crianças do Ensino Fundamental I, defendemos que as crianças da Educação Infantil, com a faixa etária acima de 5 anos, conseguiram construir a noção euclidiana de espaço; portanto, podem entender as representações espaciais de uma planta baixa.

A imersão no campo, ou seja, a realização das atividades de elaboração dos mapas sobre as vivências com os professores e as crianças, foi realizada com permissão da direção da escola e a aceitação dos professores, crianças e respectivos responsáveis, seguindo o conjunto de normas de desenvolvimento das pesquisas com crianças pequenas (CORSARO, 1997).

0 projeto seguiu os direcionamentos de uma pesquisa qualitativa, porque concordamos que o perfil desta pesquisa evoca um paradoxo científico que "consiste em interrogar um ser singular quando as ciências sociais se interessam pelo coletivo. 0 indivíduo é interrogado quando representante de um grupo social" (ALBARELLO et al, 1995, p. 85). 
Professores e alunos da unidade de Educação Infantil foram entrevistados em todas as etapas de elaboração dos mapas e demais atividades que trabalharam a visão vertical, horizontal e relação topológica. A metodologia dos mapas foi desenvolvida a partir da colagem de figuras geométricas que representam os espaços; construção de maquete de toda a unidade de ensino; tour dentro e fora da instituição de ensino, interagindo com a comunidade escolar e local; realização de desenhos dos espaços da creche, sala de aula, casa; elaboração de texto coletivo sobre a história da instituição de ensino, no qual questionamos os sujeitos de pesquisa sobre o que eles gostam e o que não gostam daquele espaço.

Esta metodologia não está pronta nem acabada, mas em constante movimento de transformação, pois os professores participaram das atividades e foram convidados a repensar as propostas, analisando e refletindo as práticas com autonomia na elaboração e/ou alteração dos planos de aula.

A pesquisa preocupou-se com as formas de registrar os usos dos espaços da instituição de Educação Infantil, nosso campo de pesquisa, pelas pessoas que lá convivem. A metodologia dos mapas sobre as vivências trabalha com a produção cartográfica das crianças, dos funcionários e dos professores. Os pesquisados foram convidados a representarem o que é mais significativo no espaço da unidade de ensino para eles.

No processo de entrevista, os participantes descreveram os seus desenhos. Fizemos a sondagem com cada aluno, funcionário e professor para tentar descobrir o porquê das escolhas de determinadas representações.

A avaliação e discussão dos dados obtidos (desenhos e gravações) com os participantes da pesquisa tiveram o intuito de selecionar falas e representações que estão presentes no mapa da instituição de ensino. A ideia foi que todos os participantes da pesquisa (professores, funcionários e alunos das duas instituições) dialogassem com as formas de representar o mapa sobre as vivências daquele espaço de pesquisa. 


\section{REFERÊNCIAS}

BIKLEN, S., BOGDAN, R. A investigação qualitativa em educação. (tradução de Alvarez, M., Santos, S., \& Baptista, T.). Porto: Porto Editora (Original publicado em 1991), 1994.

DUFFY, B. Late nineteenth-century popular educational conservatism: the work of coalminers on the school boards of the North-East. History of Education, 27 (1)m 29-38, 1998.

LESSAN, J. Geografia no ensino fundamental I. BH: Fino Traço, 2011.

LIMA, R.J. Tem que estar no mapa porque faz parte do mundo: cartografia com crianças em Areal. 2014. Dissertação (Mestrado em Educação) - Universidade Federal Fluminense, Conselho Nacional de Desenvolvimento Científico e Tecnológico.

LOPES, J.J.M. Mapa dos cheiros: cartografia com crianças pequenas. Geografares, n. 12, pp. 211-227, 2012.

NUNES, DG. Reconhecimento social da infância no Brasil: da menoridade à cidadania. In.: VASCONCELOS, V.M.R. (Org.). Educação da infância: história e política. Niterói: Editora da UFF, 2003, pp. 107-132.

OLIVEIRA, M.K. Jovens e adultos como sujeitos de conhecimento e aprendizagem. Educação como Exercício de Diversidade, p. 61, 2005.

PROUT, A. Reconsiderando a nova sociologia da infância. In.: Cadernos de pesquisa, v. 40, n.141, pp. 729-750, set./dez. 2010.

ROBERTI, D.L.P.; LOPES, J.J.M.L. Cartografias de quem produz cartografias: narrativas dos professores sobre crianças e mapas. Ateliê Geográfico, v. 12, n. 3, pp. 157-169, 2018.

EIS, A.C. A institucionalização da infância no Brasil republicano. In.: VASCONCELOS, V.M.R. (Org.). Educação da 
infância: história e política. Niterói: Editora da UFF, 2003, pp. 85-106.

SANTOS, M. Por uma outra globalização. Rio de Janeiro: Record, 2000.

SARMENTO, M.J.; MARCHI, R.C.. Radicalização da infância na segunda modernidade: Para uma Sociologia da Infância crítica. Configurações. Revista de sociologia, n. 4, pp. 91-113, 2008

SOARES, M. Letramento: um tema em três gêneros. Belo Horizonte: Autêntica, 1998.

SIMIELLI, M.E. Cartografia e ensino - Proposta e contraponto de uma obra didática. Tese de livre-docência apresentada ao Departamento de Geografia da FFCLH. Universidade de São Paulo, 1996.

TIBET, G.G.C. Os estudos da Criança e os Estudos da Infância. In.: Isto não é uma criança: Teorias e Métodos para o estudo de bebês nas distintas abordagens da Sociologia da Infância de língua inglesa. Tese de Doutorado. Programa de Pósgraduação em Educação. UFSCAR, 2013.

VIGOTSKI, L.S. Obras Escogidas. Tomo IV. Madri: Machado Libros. 2006a.

Obras Escogidas. Tomo V. Madri: Machado Libros.

$2006 b$. Imaginação e criação na infância. São Paulo: Ática, p. 16, 2009

Recebido: 26/07/2019

Revisto: 27/08/2019

Aceito: 28/08/2019

www.veracruz.edu.br/instituto

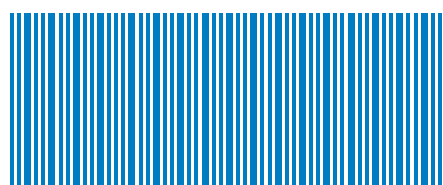

